\title{
Solution for controlling a hydraulic motor using cloud data
}

\author{
Ioana Udrea ${ }^{1, *}$, Viorel Ionut Gheorghe ${ }^{1}$, Mihai Avram ${ }^{1}$, Silviu Petrache ${ }^{1}$, Alina Popescu- \\ Cuta $^{1}$, Romeo Traian Popa ${ }^{1}$ \\ ${ }^{1}$ Mechatronics and Precision Mechanics Department, Faculty of Mechanical Engineering and \\ Mechatronics, University "POLITEHNICA" of Bucharest, RO
}

\begin{abstract}
In the last period, Internet of Things (IoT) is experiencing an increasing development, and the tendency of hosting applications and especially data, in cloud computing systems is growing. Currently, most of the Building Management System (BMS) analyse directly data or transfer it to the cloud.

In this context, the proposed solution aims to read indoor thermal climate data from cloud computing platform and based on them operate a hydraulic motor. The input data could be generated by an in-house sensor monitoring solution or by a foreign BMS system that transmits open source data to cloud.

In this study some conditions are imposed to the input data and as a result, control current is generated and transmitted in order to command proportional electro-hydraulic valve that drive a hydraulic motor. The electro-hydraulic valve is controlled with the help of an amplifier, by a data acquisition board (DAQ) that runs LabView application. With the help of the developed software, the motor speed and the direction of rotation can be controlled.

In last years, the number of requests for architectures projects with moveable elements has increased because they multiply the possible use of the buildings. With the information generated by the sensors that measure the indoor climate parameters, the hydraulic motor could be used in such a construction. Examples of atypical buildings with special functionalities that the architects would propose and that needs high torque actuation are presented in this paper.
\end{abstract}

\section{Introduction}

Internet of Things (IoT), considered by many to be one of the most important technologies of our day, has grown exponentially in recent years [1]. RFID and sensor networks are considered the fastest growing information and communication technologies among the technologies available in IoT [2]. In recent works is emphasized the development and

\footnotetext{
* Corresponding author: ioana.udrea@upb.ro, udreaioana@yahoo.com
} 
performance of wireless sensors that measure indoor climate parameters [3]. Environmental monitoring is an important IoT application which involves monitoring the surrounding environment and reporting this data for effective short term measures such as remotely controlling the heating or cooling devices and long term data analyses and measures [4]. For the past decades, as a research highlight, networked control systems (NCSs) not only have attracted the attention of many scholars but also have generated huge profits in the industry. Compared with the traditional control systems, NCSs have obvious advantages: low cost, flexibility, easy re-configurability, natural reliability, robustness to failure, and adaptation capability [5]. On the other hand, hydraulic machines are widely used in construction. Computer control can improve motion performance of a hydraulic device in this respect [6].

In this context, the present paper aims to realize a solution for controlling a hydraulic motor using cloud data.

The data will be read from an IoT platform, named ThingSpeak, and according to one of the read parameters, temperature, the control will be done. For this, a computer and a data acquisition board (DAQ) will be used. LabVIEW software will be used to read data from cloud and transform the read value into digital signal for DAQ.

It is intended that DAQ to support automatic control, according to temperature and manual control from LabVIEW [7] software interface (Front Panel). The DAQ will transform digital signal into analog one and will give it to the command unit of a hydraulic motor, see fig. 1 .

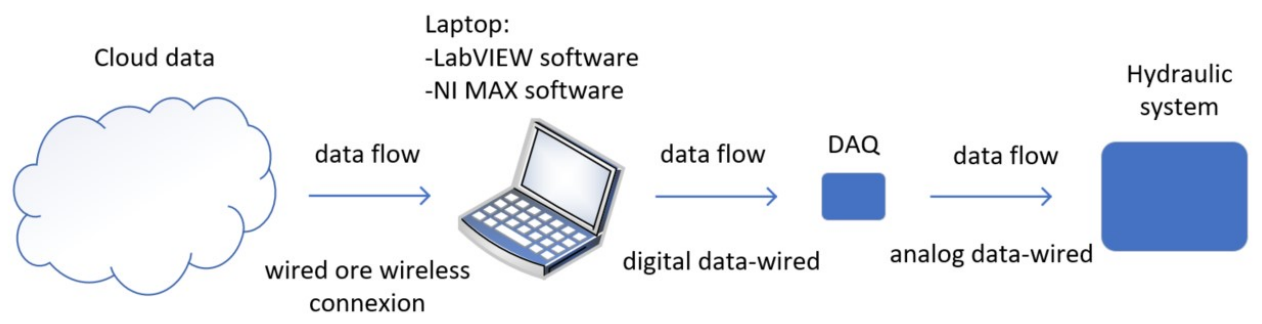

Fig. 1. Data flow in the process developed in this work

\section{Method and procedure}

This chapter presents the physical elements of the experiment: hydraulic system and data acquisition board and the virtual elements: ThingSpeak platform and data LabVIEW software.

\subsection{Hydraulic system description}

The entire hydraulic system is composed of the hydraulic part and a proportional amplifier. In fig. 2 a) is presented the hydraulic diagram, composed of: 1 - Pump unit; 2 - 4/3-way proportional valve; 3 - Rotary hydraulic motor (Sauer Danfoss OMM 8 - Orbital Motors, $\left.8.2 \mathrm{~cm}^{3}, 1950 \mathrm{~min}^{I}\right) ; 4$ - Flow meter.

In fig. 2 b) is presented the proportional amplifier and its related elements diagram: 1 Control block made with NI6009; 2 - Power supply 24Vdc; 3 - Two channel proportional amplifier; 4 - Proportional electromagnetic actuators of the 4/3-way proportional valve (FESTO, $P_{\max }: 12 \mathrm{MPa}$, ISO/DIN 4401 size 02). In fig. $2 \mathrm{c}$ ) a detail photo of pump unit can be seen (FESTO Hydraulikaggregat TN 152962, $P_{\max }=12 \mathrm{mPa}, \mathrm{V}=8 \mathrm{~cm}^{3}$ ). 


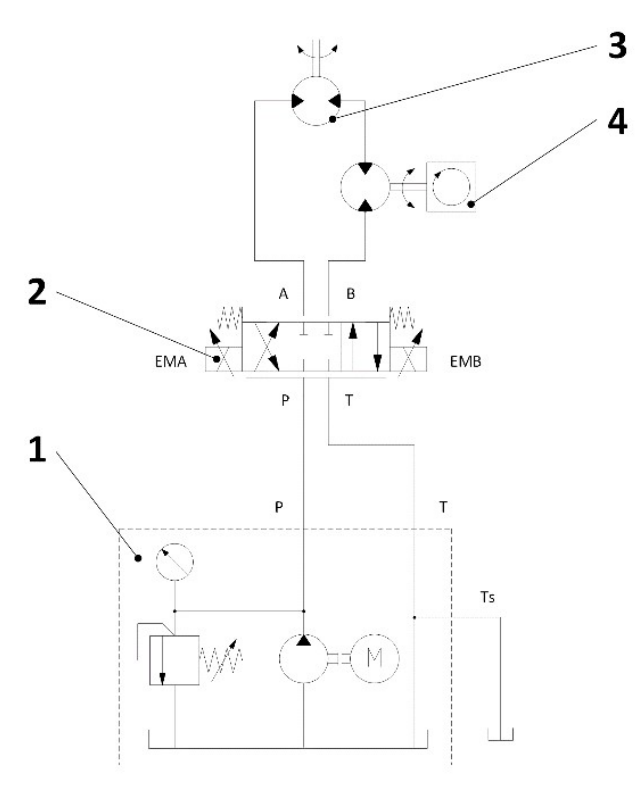

a)

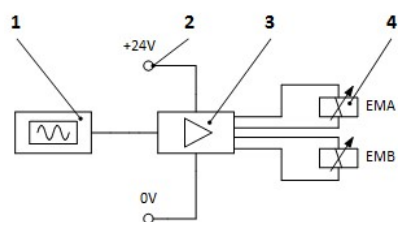

b)

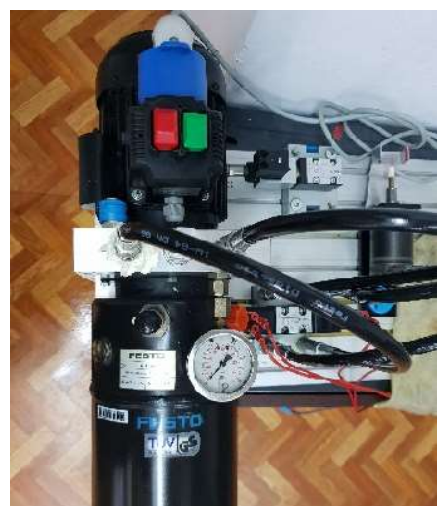

c)

Fig. 2. Elements of hydraulic system

The amplifier allows control of proportional valves. It is designed so that it can either be driven by two independent solenoids ( 1 channel) or a valve with two solenoids ( 2 channel) such as a 4/3-way proportional valve. The proportional amplifier thus works either as a 1channel amplifier or a 2-channel amplifier. The inputs are short-circuit protected or surgeproof up to $24 \mathrm{~V}$.

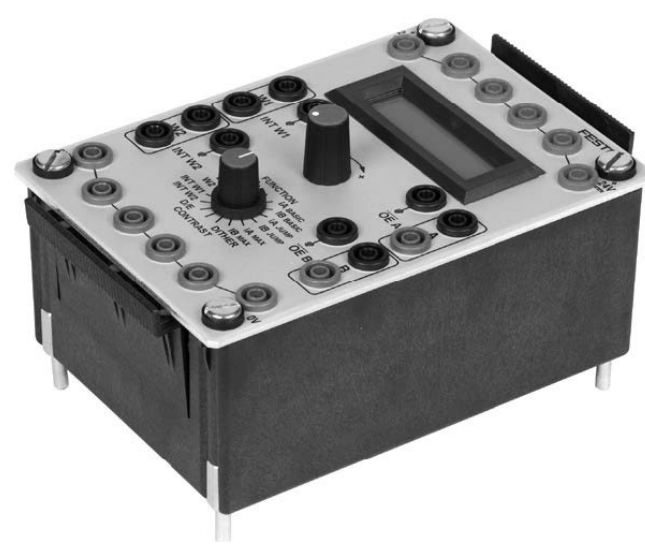

a)

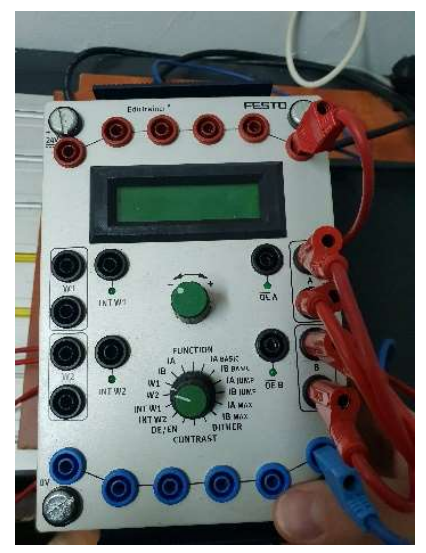

b)

Fig. 3. Proportional amplifier 162255 produced by Festo a) image from Festo web site [8]; b) photo of the amplifier used in this experiment

\subsection{ThingSpeak platform}


ThingSpeak [9] is IoT analytics platform service that allows someone to aggregate, visualize, and analyse live data streams in the cloud. One can send data to ThingSpeak from his devices, create instant visualization of live data, and send alerts. In a recent review paper [10] ThingSpeak is described as an open source platform to recover and store data over the internet.

From the ThingsSpeak platform, channel DHT22 \& BMP180_RaspberryPi will be used, see fig. 4. Here more fields are created. They show the data transmitted by sensors of indoor thermal climate parameters: temperature, humidity and pressure. A field displays the calculated value of the PMV (Predicted Mean Vote) index, based on the indoor climate parameters read by the sensors and other approximate parameters.

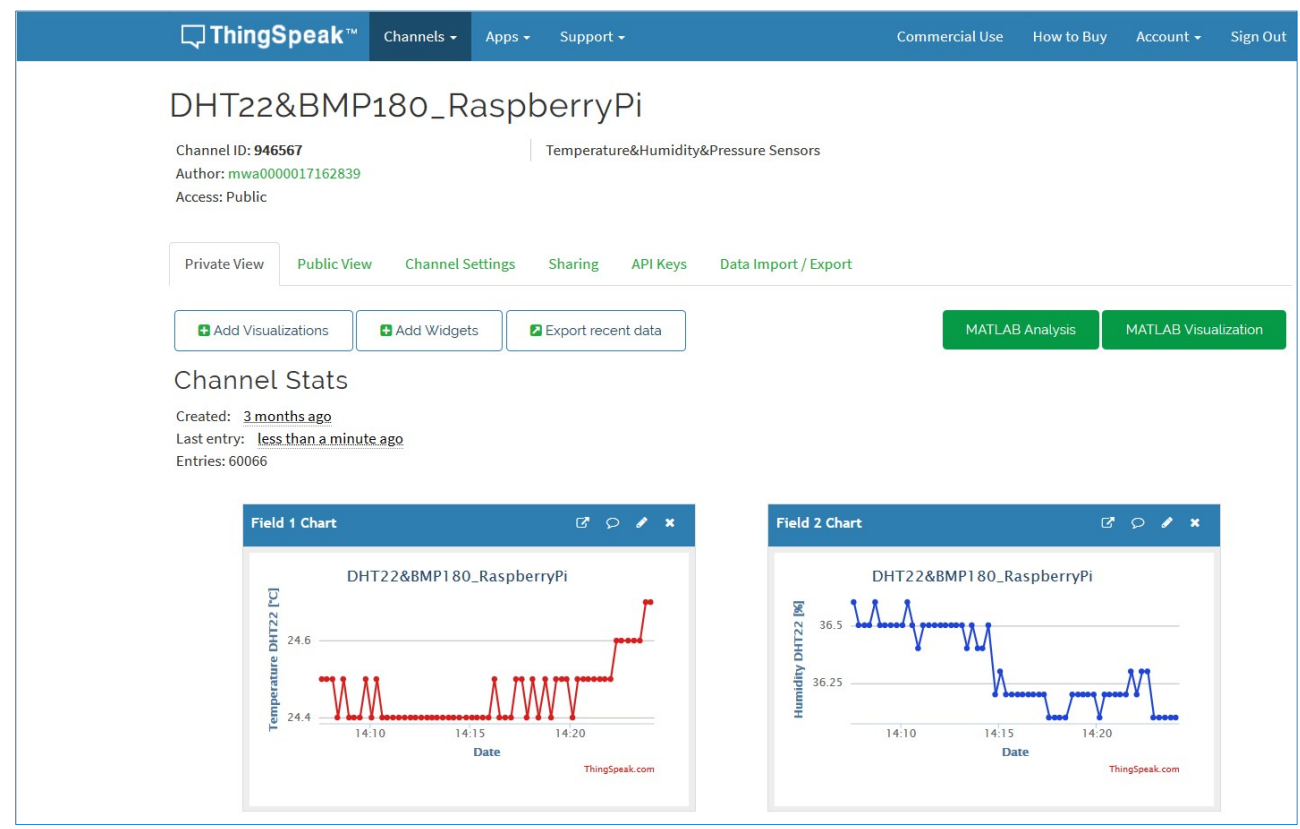

Fig. 4. The channel DHT22\&BMP180_RaspberryPi, created on ThingSpeak

\subsection{LabView software}

LabVIEW is systems engineering software for applications that require test, measurement, and control with rapid access to hardware and data insights [7]. In this work was used LabVIEW 2013 release [11]. LabVIEW offers a graphical programming approach structured in two windows: front panel which looks like a control panel in which the IN and OUT data are displayed in a user-friendly way and diagram block where one can see the actual code of the program, realized in a combination of elements and logical structures and graphical links in the form of wires between them, see fig. 8 .

\subsection{Data acquisition board (DAQ) presentation}

The National Instruments (NI) USB-6009 DAQ devices provide eight single-ended analog input (AI) channels, two analog output (AO) channels, 12 DIO channels, and a 32-bit counter with a full-speed USB interface [12]. For this DAQ National Instruments provides a software, named Measurement \& Automation Explorer (NI MAX) [13], used for managing devices and interfaces, manage installed NI software, manage virtual channels or 
tasks for devices and others. NI MAX version must be compatible with DAQ driver. For studied DAQ the installed version is NI-DAQmx 16.0.

In fig. 5 is presented an image with NI USB-6009 device, used in this work. In fig. 5 b) one can see the DAQ connected to proportional amplifier used for hydraulic system control. The DAQ pins AO 0, AO 1 and GND are connected to this device.

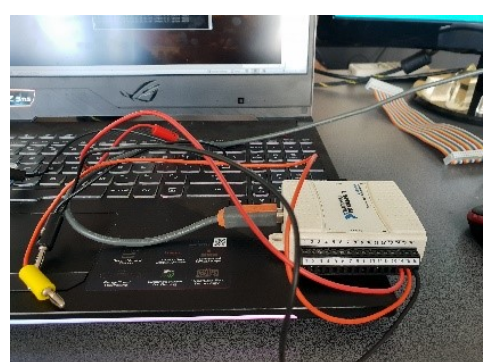

a)

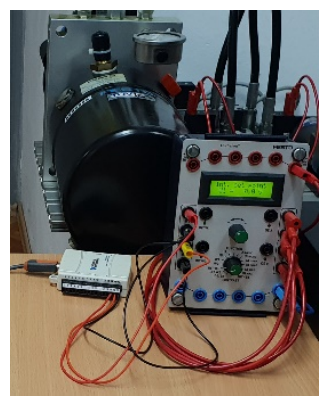

b)

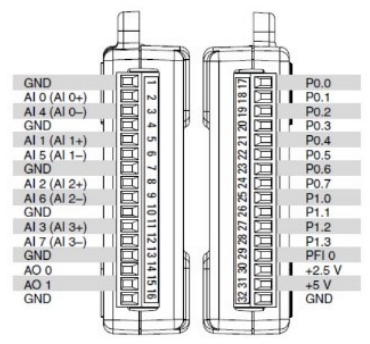

c)

Fig. 5. Data acquisition board NI USB-6009 used in this work: a) pin connectors used; b) connected with proportional amplifier; c) pinout

In fix. 6 is presented DAQ configuration, realized in NI MAX software. In fig. 6 a) a new channel, for NI USB-6009 is defined. In fig. 6 b) the DAQ output AO 0 is configured. The proportional amplifier accepts input signals named w1 and w2 with values between 0 and 5 $\mathrm{V}$. For this reason, two analog outputs have been configured for DAQ, both having values in the range $0-5 \mathrm{~V}$.

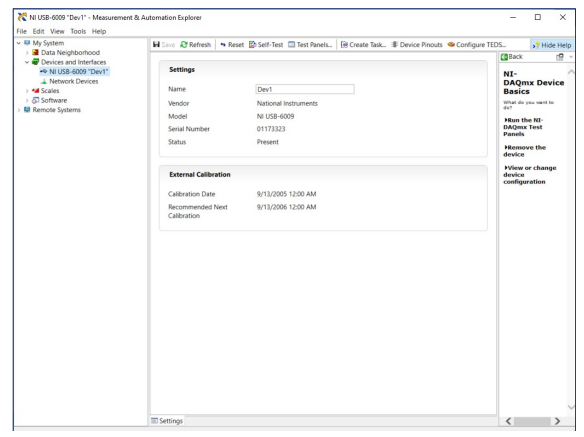

a)

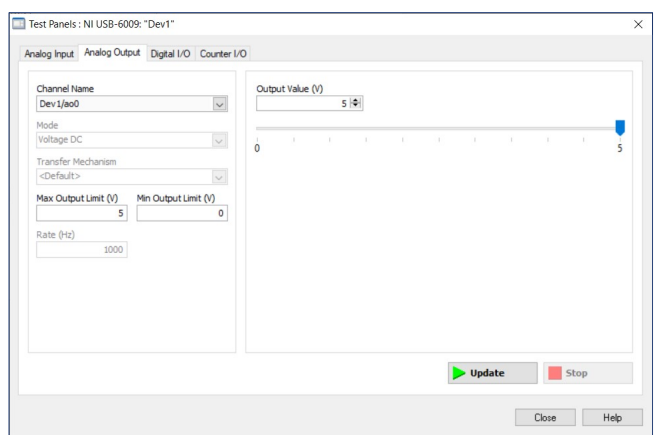

b)

Fig. 6. DAQ configuration in NI MAX: a) Channel developed for NI USB-6009; b) Analog Output

\section{Results and discussion}

The ThingSpeak channel, DHT22 \& BMP180_RaspberryPi, presented in subchap. 2.2 provides the data in json format, also.

From the data provided by json file four fields are used in the application developed in LabVIEW software. With this data, in LabVIEW are created the following graphs: Temperature $\left[{ }^{\circ} \mathrm{C}\right]$, Relative Humidity [\%], Pressure [mBar] and PMV, see fig. 7 a).

The code used for this can be seen in fig. 8. Here a subprogram, named Read from $J S O N(S u b V)$.vi is used. The subprogram has eight outputs, corresponding to instant value 
of: temperature, relative humidity, pressure, PMV and graph that shows history data for the instant values.

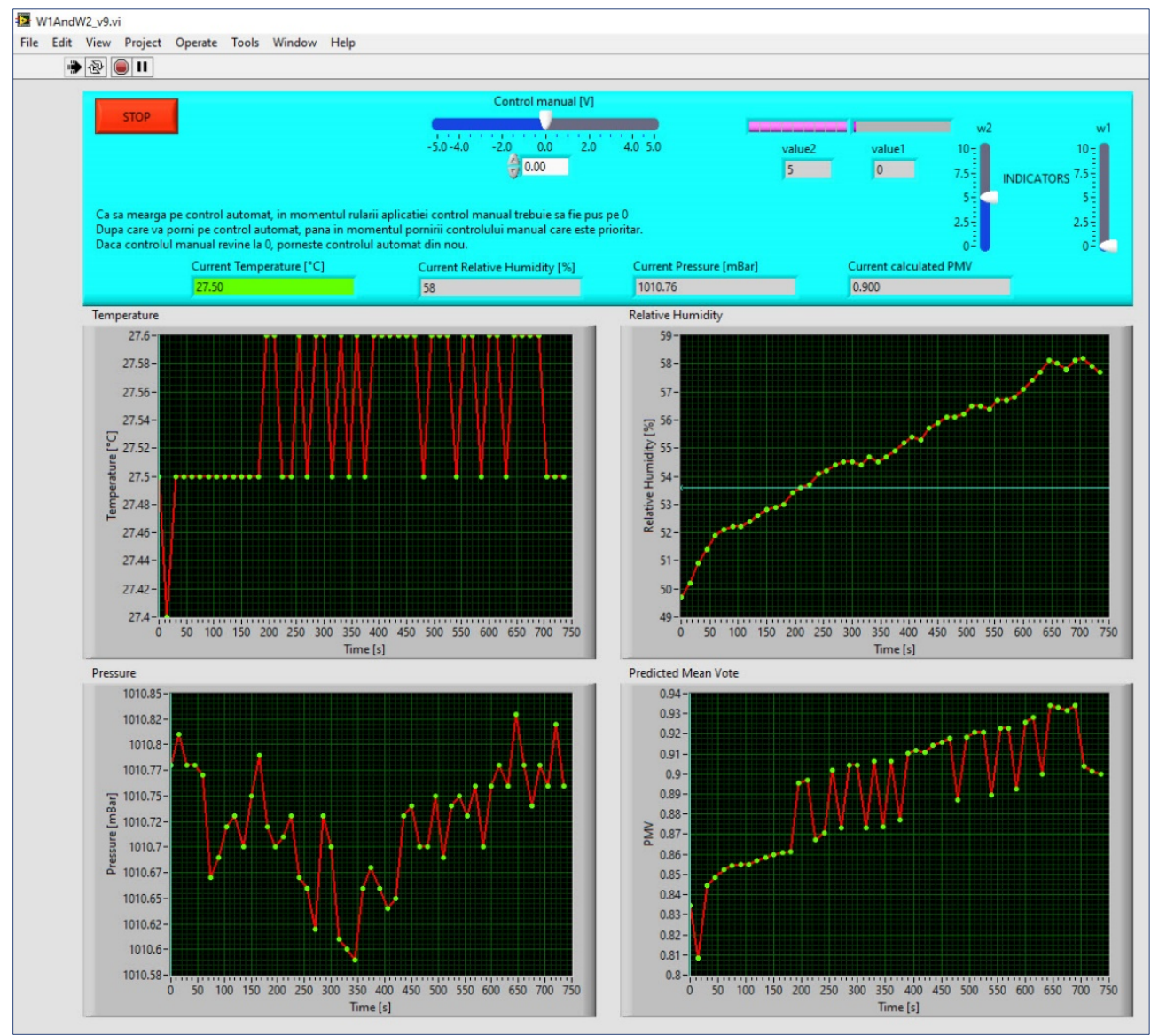

a)

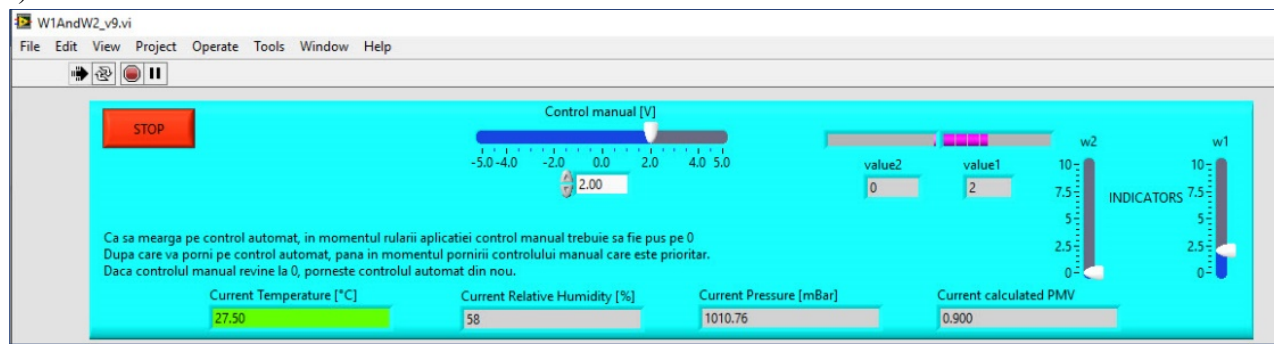

b)

Fig. 7 Application developed in LabVIEW-Front Panel a) automated control; b) manual control

The LabView main application (that use the subprogram) displays the data provided in four data fields and four graphs. It also has a decision block (Formula Node) that determines whether DAQ will receive decisions made based on temperature values or manual controls. The manual control can be in the range $-5.0-5.0 \mathrm{~V}$, see fig. 7. The data are processed and $\mathrm{w} 1$ and w2 take values in range $0-5.0 \mathrm{~V}$ each. An algorithm for temperature is also used. 


\begin{tabular}{|l|l|}
\hline Manual control & \\
\hline manual input $\mathrm{w} \in(0,5)$ & $\mathrm{w} 1=\mathrm{w} ; \mathrm{w} 2=0$ \\
\hline manual input $\mathrm{w} \in(-5,0)$ & $\mathrm{w} 1=0 ; \mathrm{w} 2=-\mathrm{w}$ \\
\hline Control based on temperature values (when $\mathrm{w}=0)$ & \\
\hline temp $<19$ & $\mathrm{w} 1=5 ; \mathrm{w} 2=0$ \\
\hline temp $\in[19,21)$ & $\mathrm{w} 1=($ temp -19$) * 5 / 2 ; \mathrm{w} 2=0 ;$ \\
\hline temp $\in[21,25.5]$ & $\mathrm{w} 1=0 ; \mathrm{w} 2=0$ \\
\hline temp $\in(25.5,27]$ & $\mathrm{w} 1=0 ; \mathrm{w} 2=\mathrm{abs}(($ temp- -27$) * 5 / 2) ;$ \\
\hline temp $>27$ & $\mathrm{w} 1=0 ; \mathrm{w} 2=5$ \\
\hline
\end{tabular}

Tab. 1 Algorithm that transform input data (manual control or automated control based on temperature) in appropriate values for DAQ

As can be seen from the tab. 1 engine speed is variable depending on the temperature value. The temperature intervals in tab. 1 are chosen according to EN15251 category limits [14].

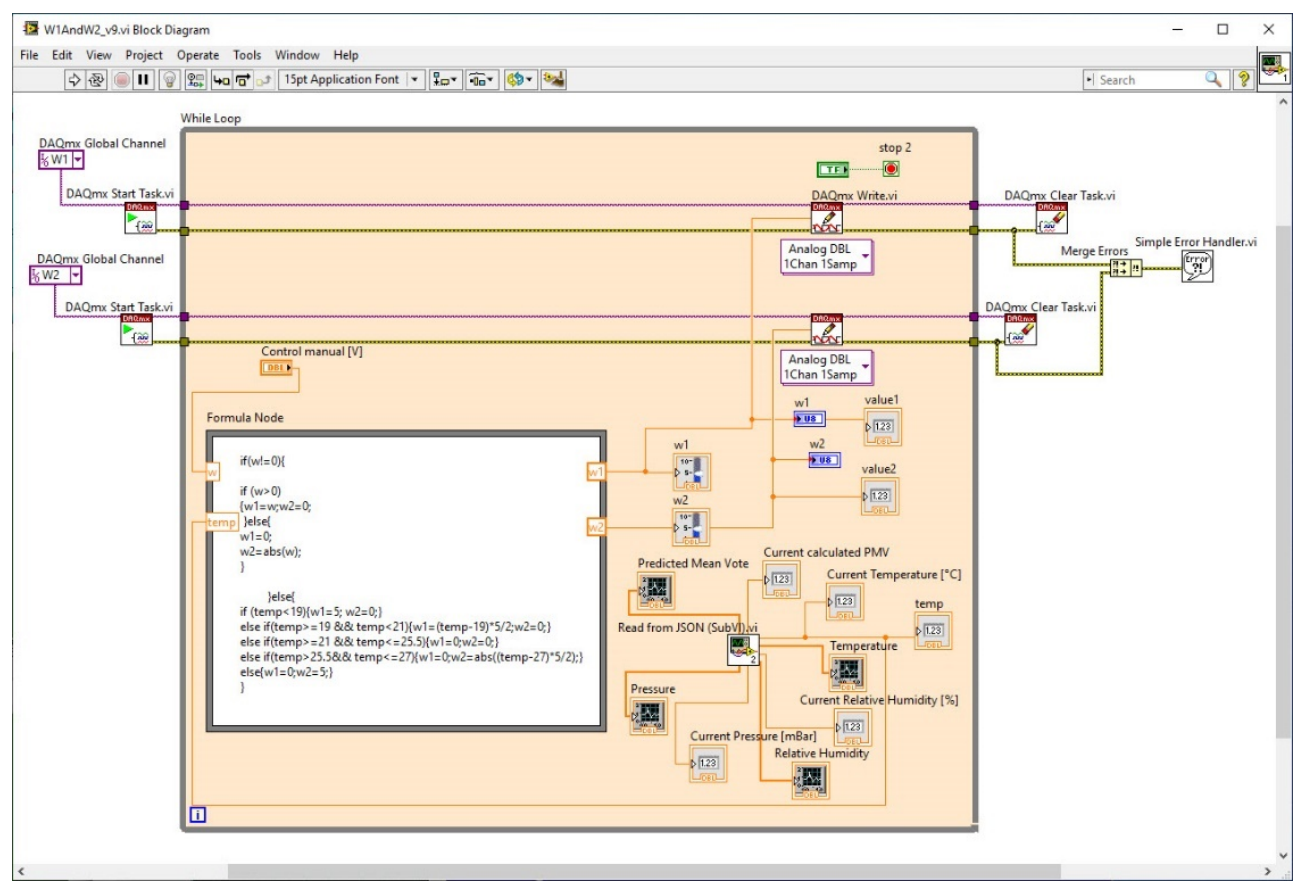

Fig. 8 Application developed in LabVIEW-Block Diagram

In fig. 7, is presented the running application. In fig. 7 a) one can see that instant temperature value is above $20^{\circ} \mathrm{C}$ threshold, so, according to tab. 1 the values for w1 and w 2 should be $w 1=0 ; \mathrm{w} 2=5$. The values were calculated correctly, this is shown by the indicators $w 1$ and w2 located in the top right of the image. In fig. 7 b) it is observed that manual control is set to a value of $2 \mathrm{~V}$. In this situation, according to tab. 1 will result $\mathrm{w} 1=2 ; \mathrm{w} 2=0$. These values are also found for the two indicators $\mathrm{w} 1$ and $\mathrm{w} 2$.

Manual control is a priority for automatic control. Automatic control only works when there is no manual control (when its corresponding variable is 0 ).

The elements in the photograph in fig. 9 can be found in the diagram in fig. 1, excepting "cloud", of course. 


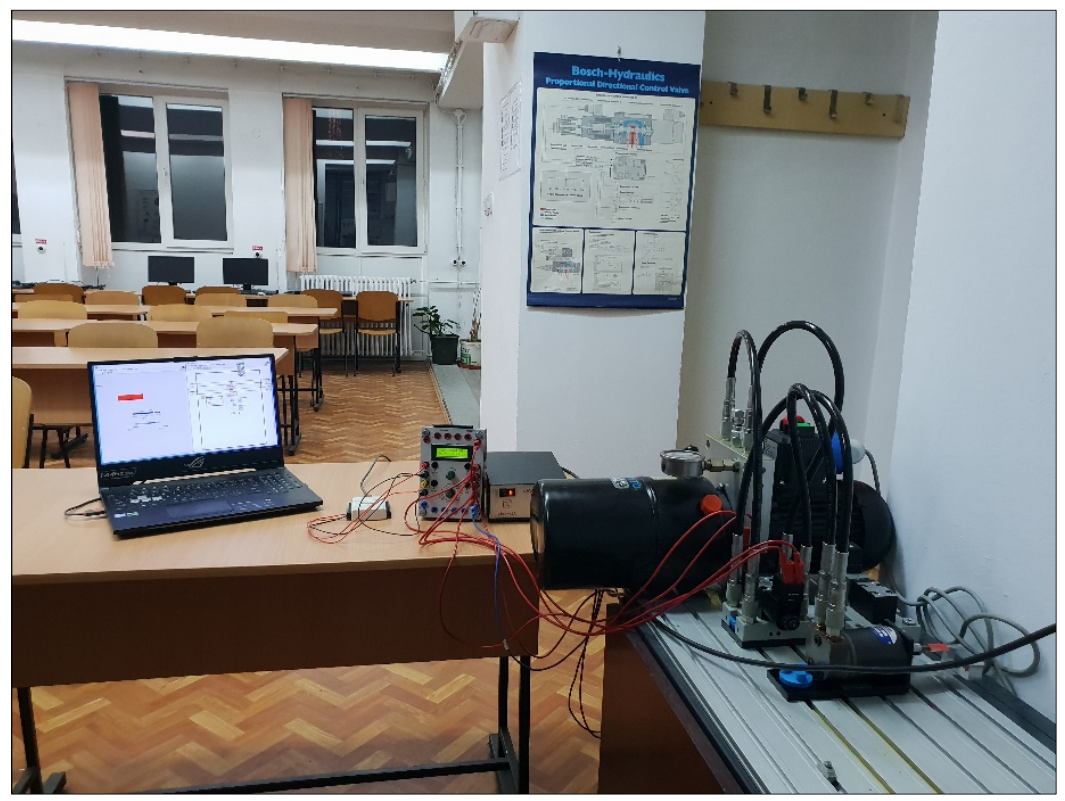

Fig. 9. Image with all elements of the experiment

\section{Conclusions}

In this paper real data from an IoT platform located on cloud are used. In this application cloud data is represented by a multi-field channel of the ThingSpeak platform. This data consists of sensor read value: temperature, relative humidity, pressure and a comfort index, PMV. Data is taken from the cloud by interpreting a json file using LabVIEW software [11]. Here is an application that processes the read data and with the help of NI-MAX [13] commands are send to a DAQ that converts the digital signal into an analog one. This is required for a digital amplifier that gives the signal to a distributor that control a rotary hydraulic motor.

Similar studies have not been found in the literature, such as applications presenting the command of a hydraulic motor based on the indoor climate parameters read by sensors, parameters located on cloud.

It is known that hydraulic actuators perform high torque actuation so they can be used for moving heavy elements of an atypical building in correlation with the indoor thermal climate parameters read by the sensors. Such as opening an atrium when exceeding certain values of temperature or thermal comfort indexes, lowering some lifts, moving some surfaces by orienting them towards certain cardinal points and other applications.

An example of an atypical construction that has a retractable roof and uses hydraulic actuation to move it, is the Amsterdam Arena [15]. The control of the hydraulic motor that determines the opening of such a roof could be made based on the interior temperature. In the case of a very large construction, such as a stadium, the cloud solution is useful, it allows the systematization of a large number of sensor systems that would be positioned in different locations of the stadium. Of course, the temperature should be correlated with the outdoor temperature so that the effect is to increase it when it is too small and decrease it when it is too high. Decisions regarding the control of the hydraulic motor can be easily taken depending on the PMV control parameter, which is provided by the studied sensor system. At a lower level, an example of a construction (village hut) whose hydraulically 
operated walls close and open depending on the temperature is in Xiahuayuan Village, China [16].

Recently, the number of requests for architectures projects with moveable elements has increased. They multiply the possible use of the buildings, in this sense, a presentation of various types of architectures with moveable elements is made by Christoph Paech [17].

Although less commonly used in buildings, hydraulic fans can be used here for ventilation [18] or as firefighting equipment [19]. In this case it is useful to control them according to the parameters of the indoor climate and even increase or decrease the speed of the fan drive motor according to indoor temperature (which is the input parameter in the case of the acting presented in this paper).

\section{References}

1. J. H. Nord, A. Koohang, J. Paliszkiewicz, The Internet of Things: Review and theoretical framework, Expert Systems With Applications, 133 (2019) 97-108, doi: https://doi.org/10.1016/j.eswa.2019.05.014

2. J. Gubbi, R. Buyya, S. Marusic, and M. Palaniswami, "Internet of Things (IoT): A vision, architectural elements, and future directions," Future Generation Computer Systems, vol. 29, no. 7, pp. 1645-1660, 2013/09/01/ 2013, doi: https://doi.org/10.1016/j.future.2013.01.010.

3. A. Mylonas, O. B. Kazanci, R. K. Andersen, B. J. Olesen, Capabilities and limitations of wireless $\mathrm{CO} 2$, temperature and relative humidity sensors, Building and Environment, (2019), doi: https://doi.org/10.1016/j.buildenv.2019.03.012

4. S. Zafar, G. Miraj, R. Baloch, D. Murtaza, K. Arshad, An IoT Based Real-Time Environmental Monitoring System Using Arduino and Cloud Service, Engineering, Technology \& Applied Science Research, Vol. 8, No. 4, (2018), 3238-3242

5. Y. Q. Xia, Y. L. Gao, L. P. Yan, M. Y. Fu, Recent Progress in Networked Control Systems - A Survey, International Journal of Automation and Computing, DOI: 10.1007/s11633-015-0894-x, (2015)

6. J. Činkelj, R. Kamnik, P. Čepon, M. Mihelj, M. Munih, Closed-loop control of hydraulic telescopic handler, Automation in Construction, 19 (2010) 954-963

7. National Instrument, LabVIEW software release 2019, https://www.ni.com/roro/shop/labview.html, (accessed March 2020)

8. Festo, Proportional amplifier 162255 (https://www.festo-didactic.com/int-en/learningsystems/equipment-sets/hydraulics/components/proportionalamplifier.htm?fbid=aW50LmVuLjU1Ny4xNy) (accessed Feb. 2020)

9. ThingSpeak, IoT Analytics Platform, https://thingspeak.com/, (2020), (accessed March 2020)

10. R. K. Dwivedi, S. Singh, R. Kumar, Integration of Wireless Sensor Networks with Cloud: A Review, 2019 9th International Conference on Cloud Computing, Data Science \& Engineering (Confluence), publisher IEEE, DOI: 10.1109/CONFLUENCE.2019.8776968

11. NI LabVIEW 2013 Release Details, http://www.ni.com/labview/release-archive/2013/, (accessed March 2020)

12. NI USB-6009, Bus-Powered Multifunction DAQ, User Guide, National Instruments, 2015,

https://www.google.com/url?sa $=t \& r c t=j \& q=\&$ esrc $=$ s\&source $=$ web $\& c d=1 \& v e d=2 a h U$ KEwjGgsbXnsToAhVJxosKHbZqDsAQFjAAegQIARAB\&url=http\%3A\%2F\%2Fww w.ni.com\%2Fpdf\%2Fmanuals\%2F371303n.pdf\&usg=AOvVaw3oYX2843098LnQYR FcHhZb, (accessed March 2020) 
13. NI MAX, National Instruments, Measurement\&Automation Explorer, version 16.0.0f0, 2016

14. EN 15251, Indoor environmental input parameters for design and assessment of energy performance of buildings addressing indoor air quality, thermal environment, lighting and acoustics, EN, 2007.

15. Retroth, A Bosh Company-References, Amsterdam Arena, https://www.boschrexroth.com/en/xc/industries/machinery-applications-andengineering/architecture-in-motion/references/references-50, (accessed Mai 2020)

16. J. Astbury, Operable Interactive Village Hut opens and closes depending on the temperature, https://www.dezeen.com/2019/06/10/operable-interactive-village-hutweiguo-xu-china/, (accessed Mai 2020)

17. C. Paech, Moveable membranes - smart solutions in the field of architecture, TensiNet Symposium 2019 "Softening the Habitats: Sustainable Innovations in Minimal Mass Structures and Lightweight Architectures", 3-5 June 2019, Politecnico di Milano, Milan, Italy, DOI: 10.30448/ts2019.3245.53

18. T. A. Dill, Hydraulic fan control, US Patent - US4441651A, 1982, https://patents.google.com/patent/US4441651A/en\#patentCitations, (accessed Mai 2020)

19. Leader - Hydraulic Fans, https://www.leader-group.company/en/firefightingequipment/fire-ventilators/hydraulic-fans, (accessed Mai 2020) 